\title{
Stories in Mathematics Teacher Education: Preservice Teachers' Experiences Creating an Important Book
}

\author{
Limin Jao
}

\begin{abstract}
This paper describes a mathematics task inspired by a children's storybook, The Important Book by Margaret Wise Brown, and how secondary mathematics preservice teachers' (PSTs') experiences with this reform-based task influenced their development as educators. Findings suggest that PSTs enjoyed the opportunity to be creative and make connections to personal experiences. Engaging in this writing task also affected PSTs' development as mathematics teachers as it allowed them to think more broadly about mathematics teaching and see the value in reform-based approaches for teaching.

I am, among other things, a mathematics educator. When I tell this to people, I tend to get responses that have negative memories and/or sentiments associated to them. "I had a horrible math teacher." Or, "I'm so bad at math." Often, this is followed by an account of how they hit a wall at so-and-so grade (typically in secondary school), how they never seemed to understand so-and-so teacher who lectured at the front of the classroom, and how they did not see the relevance of what they were learning and in general found mathematics class to be boring and unengaging. These experiences typify a traditional approach to teaching and learning that is often also characterized by teacher-centered learning through repetition and rote memorization.
\end{abstract}

In contrast, when I encourage people to share positive memories of school, they are quick to speak of activities with classmates and moments where they were able to take ownership of their learning. These experiences are akin to approaches advocated for by the mathematics reform movement: devote special attention to selecting teaching strategies to support students' individual needs; strengthen students' conceptual understanding of mathematics concepts, and increase student engagement (Hiebert, 1990; Hunter, Hunter, Jorgensen, \& Choy, 2016). Other examples of teaching strategies that align with a reform-based perspective include inquiry-based learning, the use of rich tasks that connect to students' lived experience, and student-centred learning. Research shows that reformbased approaches support deeper mathematical understanding in a wider range of learners (National Council of Teachers of Mathematics, 2000; 2014).

Research (and my not-so-scientific interactions as described above) also show that these reform-based approaches have not yet come to dominate the secondary mathematics classroom (e.g., Gainsburg, 2012; Jacobs et al., 2006). I keep this as a central focus in my role as a teacher educator. Through my work with preservice teachers (PSTs), I hope to develop educators who use reform-based approaches in their mathematics teaching practice. Approaches that result in positive learning experiences for their students 
will surely contribute to a change in the common negative discourse about mathematics education (Herbel-Eisenmann et al., 2016; Rodney, Rouleau, \& Sinclair, 2016).

Secondary school PSTs are often trained as subject specialists, and tend to choose this career path because they had positive experiences as mathematics learners; they are eager to share their love of the subject matter with others (Kyriacou \& Coulthard, 2000). Secondary PSTs typically experienced traditional teaching approaches and were successful, perhaps even thriving through this approach. It is both difficult for them to put themselves in the place of a struggling secondary mathematics student and to imagine different teaching approaches that could be more valuable to their students than the ones that were so successful for their own learning (Nathan \& Petrosino, 2003). As a result, many secondary PSTs enter their teacher education program with beliefs that mathematics should be taught using a traditional approach (Swars, Hart, Smith, Smith, \& Tolar, 2007) informed by their personal experiences as students (Lortie, 1975; Pajares, 1992; Stuart \& Thurlow, 2000). Research asserts that teachers' beliefs about teaching and learning influence their instructional practices (Levin, 2015; Wilke \& Losh, 2008). As such, it is not surprising that many novice secondary mathematics teachers teach using a traditional approach, in other words, the way that they were taught (Lewis, 2014). And so, the cycle of traditional teaching in the secondary mathematics classroom continues.

Therefore, my challenge as a teacher educator is to show to these secondary mathematics PSTs the value of reform-based approaches and to challenge their preexisting beliefs. In this paper, I describe secondary PSTs' experiences engaging in a reform-based mathematics task inspired by a popular children's story, The Important Book by Margaret Wise Brown (1949) and how this experience affected the PSTs' development as mathematics teachers.

\section{The Use of Stories and Books in Mathematics Education}

It is not a novel idea (no pun intended) for stories and children's books to be used in the mathematics classroom. Research shows them to be valuable tools to help students understand mathematics as the mathematics concepts are placed in context (Capraro \& Capraro, 2006; Cohen, 2013), a key component of the reform-based approach to mathematics instruction. Learning mathematics through and, by, stories has been also found to increase students' motivation and engagement (Ward, 2005) and strengthen mathematics understanding by clarifying students' mathematical misconceptions (Skoumpourdi \& Mpakopoulou, 2011).

Stories and books in the mathematics classroom have been found to engage both reluctant and keen mathematics learners (Furner, 2017). Books with implicit mathematics content, in which the story is the focal point and the mathematics is incidental, require the teacher to highlight the mathematics to students (Forrest, Schnabel, \& Williams, 2006). For reluctant mathematics learners, it is the story that will engage these students and it is through the teacher's efforts that they can engage with the mathematics. For example, the children's picture book, Caps for Sale (Slodbokina, 1940), follows a hat salesman trying to sell his wares. Yet, teachers may ask students to notice the different colors of hats and calculate the 
profit of his sales given the cost of "50 cents a cap." Similarly, readers of the novel, The Curious Incident of the Dog in the Night-time (Haddon, 2003), will be drawn in to the adventures of the main character, Christopher. However, students may be prompted to further explore the mathematical significance of the numbering of chapters in the book. For keen mathematics learners, the mathematics content within these books may serve as an additional point of access and intrigue. Conversely, books with explicit mathematics content put less onus on the teacher to make connections with mathematics. Again, with the same benefits to all students, the story in these books relies on the mathematics. In Cindy Neuschwander's Sir Cumference picture book series, we follow Sir Cumference's adventures in which he, for example, uses geometry to design a perfect table (1997) or uses rounding to ward off an enemy attack (2015).

Although stories and books geared towards secondary-aged mathematics students exist (including The Curious Incident of the Dog in the Night-time mentioned earlier), most examples described in the literature are of picture books to be used in elementary school contexts. Yet, I believe these picture books also have a place in a secondary mathematics classroom (see Jao \& Hall, 2018). And, while research describes the benefits of stories and books for mathematics education, these benefits are targeted to students as mathematics learners. Not yet explored is the benefit of stories and books on mathematics PSTs. In this paper, I thus focus on this gap and investigate the effect of engaging in a writing task inspired by a children's story on PSTs' development and beliefs about mathematics education.

\section{Creating an Important Book: A Mathematics Task Inspired by a Children's Story}

A mathematics teaching methods course in which I was the course instructor served as the context for this study. The secondary mathematics PSTs $(n=12)$ were enrolled in a two-year program at a Canadian faculty of education in which graduates are qualified to teach from Grades 7 through 12 .

As the instructor of the mathematics methods course, I aimed to create a situated context (Lave \& Wenger, 1991) and provide opportunities in which PSTs could experience learning in an environment that modeled a reform-based approach. The course was structured around pedagogy(e.g., social justice, technology) and content-based (e.g., algebra, geometry) themes. One class in the course focused on the theme of use of stories and books in the mathematics classroom. In this class, I read the children's book, The Important Book by Margaret Wise Brown. After I finished reading, I asked the PSTs about their impressions of the book and to comment on the structure of each page. The PSTs noted that each page described a different topic (e.g., snow) and different characteristics of the chosen topic (e.g., it is cold, it melts). The PSTs also noticed that the first and last line of each page highlighted the "most important" characteristic of the topic in the pattern of: "The important thing about __ is..." and concluding with "But the important thing about __ is...", where the characteristic from the first sentence was repeated. Finally, the PSTs remarked that the book read like a collection of poems or short stories about different topics, rather having a narrative thread woven throughout the book. 
I told the class that we would be creating our very own Important Book about mathematics. The PSTs could select a mathematics topic of their choosing, write their contribution to the book, and post their "page" to the course website for the group to enjoy.

In order to create a rich narrative to describe PSTs' experiences and responses to The Important Book task, I supplemented my lived experiences in-class with written artifacts from the course. Field notes documenting PSTs' in-the-moment reactions to the task were taken both in the class that the task was assigned and in the subsequent class after the creation of their Important Book. Written artifacts consisted of their contributions to The Important Book, questionnaires, and reflective essays.

PSTs completed a questionnaire in the first class of the course so that I (as the course instructor) could get to know the PSTs in order to adapt the course to better meet their needs. Adapted from McDougall's (2004) Attitudes and Practices to Teaching Math Survey, the questionnaire had three sections. The first section asked the PSTs questions about their background in mathematics (e.g., List your previous degrees. Did you enjoy mathematics as a student?). The second section contained Likert-type questions about participants' beliefs about mathematics education (e.g., Teachers should be the ones to explain concepts to students. It is important to teach mathematics embedded into real-life problems). The final section comprised open-ended questions for PSTs to elaborate on their current beliefs (e.g., In your opinion, what teaching strategy/strategies is/are most effective for students to learn math?). The PSTs completed sections two and three of the questionnaire again at the end of the course.

The reflective essay was the final assignment of the course. In the essay, PSTs reflected on their journey of becoming a teacher of mathematics by describing their previous experiences as mathematics students, significant moments from the mathematics methods course, and any other relevant experiences. PSTs were also asked to reflect on their questionnaires, taking note of any similarities or differences between responses from the beginning and end of the course. Data were coded through a constant comparison analysis method (Glaser \& Strauss, 1999). The initial inductive coding scheme was based on themes from literature and was deductively elaborated on based on emerging themes from the data.

\section{Examples of Preservice Teachers' Writing}

In this section, I present three excerpts from The Important Book created in the mathematics methods course to give a sense of PSTs' responses to the task. All student names are pseudonyms.

$\frac{\text { Problem Solving }}{\text { By Sylvia }}$

The important thing about problem solving is the process.

There is usually more than one way to answer a request, So start with the question and do not stress!

We define the problem and know how to proceed, A plan or a strategy is how to succeed! 
But alas! Don't rush to the end.

Take time to organize is what I recommend.

Information to solve the problem is in the question, Make a column or list is my small suggestion.

Now remember in math there are important rules, Common sense, theorems, and concepts are just some of the tools, Plus properties and definitions to prove we aren't fools.

Evaluate or solve and be sure to take care, Double check your solution for errors could be there!

The final step you should do and do not delay, State the answer in a sentence makes it clear as day.

The last thing I'Il say I'm sure you can guess, The important thing about problem solving is the process.

\section{$\underline{\text { A tale of most functions }}$}

By Rafeef

The important thing about functions is every $x$ has only one $y$

Although $x$ might be exclusive, y certainly is not

And that my friend is why the vertical line test is sought

Some common functions we cover are linear and quadratic

These functions are simplistic, and some might say pretty anticlimactic

We do concentrate a bit on those within trig

These concepts are in 10 and are pretty big

Lest not forget those that are exponential and inverse

To graph such functions we need to rehearse

The functions we often dislike are those that are in pieces

We tend to get stumped when domain and range ceases

Evaluating occurs through replacing and rearranging

While simplifying occurs through expanding and changing

You will then further decipher what's even and odd

And on that note you will be awed

In 11 you will learn how to write function notation

And by the end you will be an expert on relations

Last but not least you will investigate transformations

And that my friend - is a frustration!

The important thing about functions is every $\mathrm{x}$ has only one $\mathrm{y}$ 


\section{Correlation \\ By Maya}

The important thing about correlation is that it is not causation

But it is an important measure of relation.

Correlation can be strong, and correlation can be weak.

Correlation can be found wherever you seek.

Correlation can be measured with the Pearson Coefficient,

But in non-linear situations this is quite deficient.

It is also tricked when outliers are met,

But do not despair, other choices we can get.

One idea is a non-parametric test

Like Spearman's, Kendall's, and all the rest.

But don't forget visual inspection,

And that a correlation will not necessarily answer your question,

Because the important thing about correlation, is that it is not causation.

\section{Preservice Teachers' Reactions to The Important Book Task}

Analysis of the data suggest that the task inspired by The Important Book provided PSTs with an opportunity to experience engaging with mathematics that was meaningful and satisfying. In this section, I describe PSTs' experiences as mathematics students in secondary school and how these shaped their early beliefs about mathematics teaching, PSTs' reflections of the task, and how this task contributed to the PSTs' development as mathematics teachers.

\section{Preservice Teachers' Experiences as Mathematics Learners and Early Beliefs About Mathematics Teaching}

PSTs described their learning experiences as secondary mathematics students to be largely traditional with many using the term "chalk and talk" to describe a situation where the teacher is positioned at the chalkboard lecturing to the students. Maya described a typical mathematics lesson in her secondary school as: "Teacher stands at front, takes up previous homework, teaches lesson and [goes through] examples, takes questions, then provides free time for homework." This structure was echoed by all of the PSTs.

At the beginning of the methods course, many of the PSTs believed that they would use traditional teaching practices in their own classrooms, having had academic success themselves learning in this way. Langston shared his belief that the best way to teach mathematics would be through "[teacher-led] guided practice." Emily indicated her belief that students should be "[showed] a process/sample question" followed by the teacher "replicating the process and (allowing students to) ask any questions along the way." Emily affirmed her beliefs by saying, "The way I learned worked for me, [so] why wouldn't it work for my own students?"

These beliefs, however, were not unanimous amongst the PSTs. Some PSTs believed that the "best approach" may "depend on the student." When describing their experiences as mathematics students, 
PSTs reflected that strong mathematics students (including themselves) could successfully engage and learn through this approach. For example, Justin described mathematics classes in his secondary school to be "somewhat dominated by the more talented students in the class." As such, some PSTs were uncertain whether the traditional approach would be equally successful with weaker students. In thinking about how best to support all students in their future mathematics classes, some PSTs had more tentative beliefs. For example, Justin indicated that a best approach would be "something more than chalk and talk every day," whereas Maya simply said, "I don't know."

\section{Preservice Teachers' Reactions to, and Reflections on, The Important Book Task}

When I presented the task to the PSTs, many were initially uncomfortable with the idea of writing about mathematics. None of the PSTs had experienced a similar task in previous mathematics learning contexts. Here, in a context in which they typically thrived (the mathematics classroom), the PSTs were being asked to engage in a medium in which they lacked confidence (creative writing). Within a couple days of being given the task, the PSTs began to post their pages on the course website. While all PSTs followed the general structure of pages from the book (i.e., beginning and ending their writing with the same descriptive sentence__ "The important thing about___ is that___, and providing multiple sentences each describing a different attribute of the mathematics concept), most PSTs extended the structure by adding additional features. These included using rhyming couplets, writing more than twice the number of sentences that generally occurred on a page, and hyperlinking key mathematics terms (to websites that allowed readers to enrich their mathematical understanding). While PSTs described the concepts using mathematically sound definitions, they also made connections to real-life applications and linked concepts to emotions and personal experiences.

PSTs came to the next class eager to give positive feedback to their classmates and to get feedback about their own creations. This positive energy was in stark contrast to the silence and hesitation when first presented with the task. Now, the PSTs were animatedly talking about the task, sharing how much they enjoyed it (and how surprised they were at their enjoyment), and applauding the mathematical understanding that was communicated in this creative medium.

\section{The Impact of The Important Book Task on Preservice Teachers' Beliefs}

The Important Book task allowed PSTs to experience doing mathematics in a reformed way. As an approach that was in contrast to those that they had experienced as secondary mathematics students, the positive experience of The Important Book task expanded their perspectives about what mathematics teaching could be and made them question their initial traditional beliefs about mathematics teaching.

PSTs shared that The Important Book task was a valuable and interdisciplinary approach to teaching. PSTs shared their perceptions of the many benefits to this approach for students. For example, Nikki wrote that the integration of stories into the mathematics classroom would "make students more engaged, and also develop their skills more deeply in both of these subject areas." Other PSTs felt that such tasks would allow reluctant mathematics students the opportunity to bring other areas of interest and strength 
into the mathematics classroom. Specifically, PSTs believed that students who enjoy English Language Arts and/or expressing themselves through words can also thrive in the mathematics classroom.

Likewise, PSTs shared that interdisciplinary teaching approaches could be meaningful for teachers. Although they were all passionate about mathematics, PSTs felt that these approaches would allow them to integrate other interests and passions. In the final reflection paper for the course, Mahmoud wrote:

As someone who also has an interest in English Language Arts, I would like to in the future find more ways of implementing English Language Arts into math and vice versa. In the future, I could see myself for certain assessments in math having students write a paragraph or story describing their process to solve a particular problem, or even a poem to achieve that same purpose.

Having had the positive experience of The Important Book task in the mathematics methods course, Mahmoud was now considering ways to integrate writing into his mathematics teaching, suggesting options including writing paragraphs, stories, and poems. Mahmoud also extended writing in the mathematics classroom beyond an in-class task/activity and suggested it as a possible assessment tool.

At the end of the course, when reflecting on their evolving beliefs about mathematics education, PSTs wrote of realizing that the traditional approach to teaching mathematics may not be the only approach and that "new and creative ways to teach" were needed in their teaching repertoire. PSTs reflected that their previous experiences as mathematics students contributed to early beliefs about teaching mathematics, but as a result of experiences in the mathematics methods course, including The Important Book task, their perspectives about mathematics teaching were beginning to shift. For example, in her final reflection paper for the course, Sylvia wrote:

I (reflect on) my own experiences as a student in mathematics...of "chalk and talk" lessons. I hope that as a teacher of mathematics I will create experiences for my students that are memorable and go beyond just "chalk and talk" lessons. I now think it is important that teachers plan lessons that encourage creative and critical thinking in non-traditional ways.

Similarly, Emily was able to reflect on her evolving beliefs. Thinking back to her beliefs at the beginning of the course, she wrote, "My own high school math experiences really influenced my [initial teaching beliefs]...I experienced math in a very traditional manner, I enjoyed it and couldn't really picture any other way a math classroom could exist." Emily continued to describe her new perspective to mathematics teaching by writing:

I have now realized that there are probably more effective practices or that there should exist a balance within the classroom between traditional and non-traditional teaching methods. I want to find ways to help get my students interested and excited about math and I think that a student-centred approach and including more interactive activities is a great way to achieve greater student engagement.

Cognizant of these nascent beliefs, Emily shared that more time and experience is required for her to fully develop her ideas and to develop teaching approaches and strategies that she did not herself experience as a mathematics student. She wrote, "I continue to learn about other ways that I can facilitate 
Stories in Mathematics Teacher Education: Preservice Teachers' Experiences Creating an Important Book

learning in my own classroom. I continue to learn and discover how I can inspire my own students' interest and even love of mathematics."

\section{Concluding Thoughts}

A good story can leave a lasting impression, whether it be the context or content of the story that was personally meaningful or satisfying, or the context in which the story was read (e.g., with a loved one, with friends, in quiet solitude) that was memorable. Authors of stories reap additional benefits, among them: having a direct connection to the material and seeing others enjoy their work. When assigning The Important Book task to my secondary mathematics PSTs, while I expected them to reap these particular benefits, I was unprepared for the extent to which the task would affect their thinking as mathematics educators.

In this task that combined literature and mathematics, the PSTs had the opportunity to be creative and make connections. The task of writing about a mathematics concept in the style of The Important Book is an example of integrating storybooks into the mathematics classroom. While some researchers (e.g., Honey, Pearson, \& Schweingruber, 2014; Klein, 1996) claim that it is challenging to meaningfully integrate mathematics with other subjects, others assert that this cross-curricular approach positively extends students' learning. Specifically, Austin, Thompson, and Beckman (2005) stated that this approach deepens conceptual understanding and strengthens skills in both mathematics and English Language Arts - a belief shared by my PSTs. In their contributions to the class' Important Book, the PSTs demonstrated their mathematics and language abilities through their use of various literary devices and mathematically sound descriptors. Through describing the real-world application of their chosen mathematics concepts, the PSTs also highlighted the wide applicability of mathematics in numerous contexts (Van den HeuvelPanhuizen \& Drijvers, 2014; Whitin \& Whitin, 2004). In addition, the emotional satisfaction and enjoyment of the task created positive memories for the PSTs. The sense of community developed as a result of this collective effort of creating the class' Important Book, and reciprocal appreciation for individual PSTs' contributions, only appear to strengthen the value of this task. While tasks inspired by The Important Book have been taken up in elementary mathematics contexts (e.g., Bertheau \& Theissen, 1994; Whitin \& Piwko, 2008), the positive reactions of my secondary mathematics PSTs suggest applications in secondary and even tertiary contexts.

The Important Book task also had an impact on the PSTs as developing mathematics educators. A task inspired from a storybook pushed these future mathematics teachers to reflect on assumptions about secondary school mathematics that they had accumulated as mathematics learners themselves through their apprenticeship of observation (Lortie, 1975). Here, PSTs experienced an "extreme example of innovative practice" to counteract PSTs' beliefs about teaching (Grossman, 1991, p. 350). The "extreme" nature of this task was not in its feasibility in the secondary mathematics classroom; rather, engaging in this reform-based task was vastly different from the PSTs' previous mathematics learning experiences using traditional approaches. This new experience led the PSTs to think more broadly about their teaching practice. Grossman (1991) asserts that these "extreme" experiences stick with PSTs, 
and once in the workplace, elements of reform-based approaches will be retained in their teaching practice as they instinctively drift back towards using traditional approaches. Thus, it is important for teacher education programs to provide as many (extreme) opportunities for PSTs to experience mathematics using reform-based approaches, especially those that counter their own experiences as mathematics students. Participating in these meaningful and authentic learning experiences is not only gratifying for the PSTs as mathematics learners, but also increases the likelihood that they will implement these valuable approaches into their own teaching practice (Kilpatrick, Swafford, \& Findell, 2001; Leavy \& Hourigan, 2018).

\section{References}

Austin, R. A., Thompson, D. R., \& Beckmann, C. E. (2005). Exploring measurement concepts through literature: Natural links across disciplines. Mathematics Teaching in the Middle School, 10(5), 218-224.

Bertheau, M., \& Thiessen, D. (1994). The most important thing is... Teaching Children Mathematics, 1(2), $112-116$.

Brown, M. W. (1949). The important book. New York, NY: HarperCollins.

Capraro, R. M., \& Capraro, M. M. (2006). Are you really going to read us a story? Learning geometry through children's mathematics literature. Reading Psychology, 27, 21-36.

Cohen, M. D. (2013). Truth \& beauty: Mathematics in literature. Mathematics Teacher, 106(7), 534-539.

Forrest, K., Schnabel, D., \& Williams, M. E. (2006). Mathematics and literature, anyone? Teaching Children Mathematics, 13(4), 216-217.

Furner, J. M. (2017). Helping all students become Einstein's using bibliotherapy when teaching mathematics to prepare students for a STEM world. Pedagogical Research, 2(1), 1-11.

Gainsburg, J. (2012). Why new mathematics teachers do or don't use practices emphasized in their credential program. Journal of Mathematics Teacher Education, 15(5), 359-379.

Glaser, B. G., \& Strauss, A. L. (1999). Discovery of grounded theory: Strategies for qualitative research. New York, NY: Routledge.

Grossman, P. (1991). Overcoming the apprenticeship of observation in teacher education coursework. Teaching and Teacher Education, 7(4), 345-357.

Haddon, M. (2003). The curious incident of the dog in the night-time. London: Vintage.

Herbel-Eisenmann, B., Pape, S. J., Sinclair, N., Stephan, M., Chval, K. B., Wanko, J. J., et al. (2016). Positioning mathematics education researchers to influence storylines. Journal for Research in Mathematics Education, 47(2), 102-117.

Hiebert, J. (1990). The role of routine procedures in the development of mathematical competence. In T. J. Cooney \& C. R. Hirsh (Eds.), Teaching \& learning mathematics in the 1990s (pp. 31-40). Reston, VA: National Council of Teachers of Mathematics. 
Honey, M., Pearson, G., \& Schweingruber, H. (Eds.). (2014). STEM integration in K-12 education: Status, prospects, and an agenda for research. Washington, DC: National Academies Press.

Hunter, R., Hunter, J., Jorgensen, R., \& Choy, B. H. (2016). Innovative and powerful pedagogical practices in mathematics education. In K. Makar, S. Dole, J. Visnovska, M. Goos, A. Bennison, \& K. Fry (Eds.), Research in mathematics education in Australasia 2012-2015 (pp. 213-234). Singapore: Springer.

Jacobs, J., Hiebert, J., Givvin, K., Hollingsworth, H., Garnier, H., \& Wearne, D. (2006). Does eighth-grade mathematics teaching in the United States align with the NCTM Standards? Results from the TIMSS 1999 video studies. Journal for Research in Mathematics Education, 37(1), 5-32.

Jao, L., \& Hall, J. (2018). The important things about writing in secondary mathematics classes. The Australian Mathematics Teacher, 74(1), 13-19.

Kilpatrick, J., Swafford, J., \& Findell, B. (2001). Adding it up: Helping children learn mathematics. Washington, DC: National Academies Press.

Klein, J. T. (1996). Crossing boundaries: Knowledge, disciplinarities, interdisciplinarities. Charlottesville, VA: University Press of Virginia.

Kyriacou, C., \& Coulthard, M. (2000). Undergraduates' views of teaching as a career choice. Journal of Education for Teaching: International Research and Pedagogy, 26(2), 117-126.

Lave, J., \& Wenger, E. (1991). Situated learning: Legitimate peripheral participation. Cambridge, UK: Cambridge University Press.

Leavy, A., \& Hourigan, M. (2018). The beliefs of 'tomorrow's teachers' about mathematics: precipitating change in beliefs as a result of participation in an initial teacher education programme. International Journal of Mathematical Education in Science and Technology, 1-19.

Levin, B. B. (2015). The development of teachers' beliefs. In H. Fives \& M. G. Gill (Eds.), International handbook of research on teachers' beliefs (pp. 48-65). New York, NY: Routledge.

Lewis, G. M. (2014). Implementing a reform-oriented pedagogy: Challenges for novice secondary mathematics teachers. Mathematics Education Research Journal, 26(2), 399-419.

Lortie, D. (1975). Schoolteacher: A sociological study. Chicago, IL: University of Chicago Press.

McDougall, D. (2004). PRIME school mathematics improvement: Leadership handbook. Toronto, ON: Nelson.

Nathan, M. J., \& Petrosino, A. (2003). Expert blind spot among preservice teachers. American Educational Research Journal, 40(4), 905-928.

National Council of Teachers of Mathematics. (2000). Principles and standards for school mathematics. Reston, VA: Author.

National Council of Teachers of Mathematics. (2014). Principles to actions: Ensuring mathematical success for all. Reston, VA: Author.

Neuschwander, C. (1997). Sir Cumference and the first round table. Watertown, MA: Charlesbridge.

Neuschwander, C. (2015). Sir Cumference and the roundabout battle. Watertown, MA: Charlesbridge. 
Pajares, M. F. (1992). Teachers' beliefs and educational research: Cleaning up a messy construct. Review of Educational Research, 62(3), 307-332.

Rodney, S., Rouleau, A., \& Sinclair, N. (2016). A tale of two metaphors: Storylines about mathematics education in Canadian national media. Canadian Journal of Science, Mathematics and Technology Education, 16(4), 389-401.

Skoumpourdi, C., \& Mpakopoulou, I. (2011). The prints: A picture book for pre-formal geometry. Early Childhood Education Journal, 39, 197-206.

Slobodkina, E. (1940). Caps for sale. New York, NY: Live Oak Media.

Stuart, C., \& Thurlow, D. (2000). Making it their own: Preservice teachers' experiences, beliefs, and classroom practices. Journal of Teacher Education, 51(2), 113-121.

Swars, S., Hart, L. C., Smith, S. Z., Smith, M. E., \& Tolar, T. (2007). A longitudinal study of elementary pre-service teachers' mathematics beliefs and content knowledge. School Science and Mathematics, 107(8), 325-335.

Van den Heuvel-Panhuizen, M., \& Drijvers, P. (2014). Realistic mathematics education. In S. Lerman (Ed.), Encyclopedia of mathematics education (pp. 521-525). Netherlands: Springer.

Ward, R. A. (2005). Using children's literature to inspire K-8 preservice teachers' future mathematics pedagogy. The Reading Teacher, 59(2), 132-143.

Whitin, D. J., \& Piwko, M. (2008). Mathematics and poetry: The right connection. Beyond the Journal: Young Children on the Web, 1-8.

Whitin, D. J., \& Whitin, P. (2004). New visions for linking literature and mathematics. Urbana, IL: National Council of Teachers of English; Reston, VA: National Council of Teachers of Mathematics.

Wilke, R. A., \& Losh, S. C. (2008). Beyond belief: Preservice teachers' planned instructional strategies. Action in Teacher Education, 30(3), 64-73.

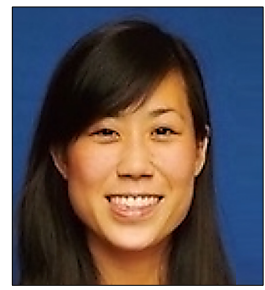

Limin Jao is an Assistant Professor in the Department of Integrated Studies in Education at McGill University. A former mathematics and science classroom teacher, Dr. Jao has experience teaching in both elementary and secondary schools as well as nontraditional settings including the Ontario Science Centre and Royal Ontario Museum. Her research focuses on issues of exemplary mathematics teaching practice, teacher beliefs and identity, and in-service and preservice teacher education. 